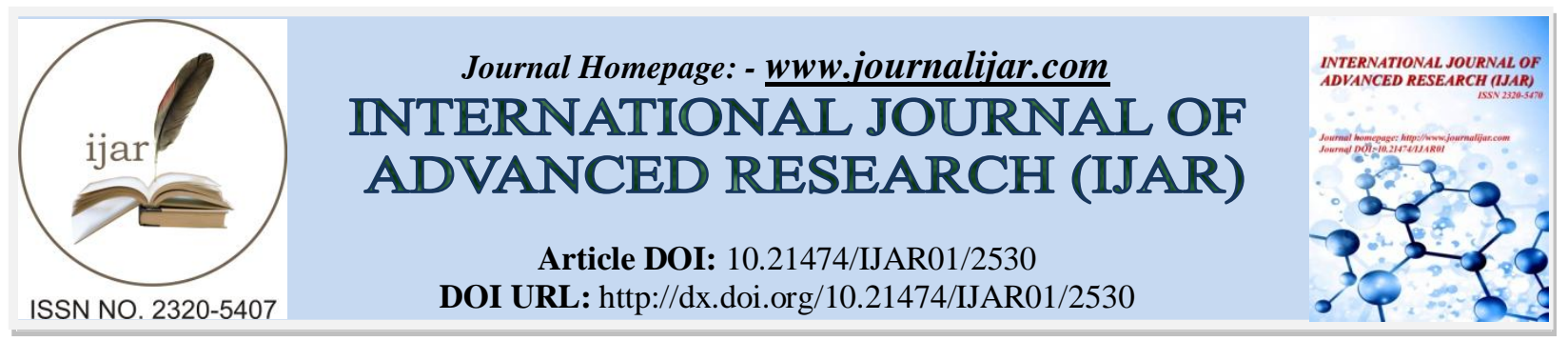

RESEARCH ARTICLE

\title{
AN ASSESSMENT OF PHYSICAL ACTIVITY INDEX BETWEEN INDIAN AND FOREIGN FEMALE STUDENTS OF DELHI STATE
}

\author{
Dr. Thingnam Nandalal Singh ${ }^{1}$ and Dr. Naveen Kumar ${ }^{2}$. \\ 1. Associate Professor, Department of Physical Education, Panjab University, Chandigarh. \\ 2. Physical Education Teacher, RPVV Civil Lines, Department of Education, NCT of Delhi.
}

\section{Manuscript Info}

........................

Manuscript History

Received: 25 October 2016

Final Accepted: 23 November 2016

Published: December 2016

Key words:-

Physical Activity Index, Indian Female Students and Foreign Female Student.

\section{Abstract}

The purpose of the study was to assess the physical activity index between Indian and Foreign female students of Delhi State. To achieve the objective of the study, two hundred $(\mathrm{N}=200)$ Indian female students and two hundred $(\mathrm{N}=200)$ Foreign female students between 17 to 25 years were selected conveniently and purposely from the regular students of different Universities and colleges of Delhi State as subjects. Physical Activity Index Questionnaire (B. Mayfield, Personal Nutritional Department, 2006) was used to assess physical activity index of students. To determine the significant difference between the mean scores of Indian and Foreign female students on physical activity index, ' $\mathrm{t}$ ' test was employed with the help of SPSS software. The level of significance was set at 0.05 . Results of the study revealed that there was no significant difference found on physical activity index between Indian female and foreign female students of Delhi State.

Copy Right, IJAR, 2016,. All rights reserved.

\section{Introduction:-}

The age of developing lifestyle diseases like high blood pressure, diabetes and heart diseases has reduced by about twenty years in the last three decades. These diseases used to be seen at 50 plus age, has recently started appearing at the age of 20-25 years. All these diseases are related to wrong lifestyle - the most important being excess Stress or Tension Stress is common because of tremendous aspirations, fast track of life, competitions, lack of time, work overload, information, overload and requirement overload. Besides Stress - obesity, salty and fatty food, lack of physical activity and exercise, smoking/tobacco, alcohol, fewer intakes of fruits and vegetables are some of the causes of deadly diseases like heart disease, high BP and diabetes.

A study conducted in 2011 which observed 46000 urban Indians showed that $78 \%$ men between 30-34 years run the risk of heart attack of these 54\% were overweight, 32\% had high blood pressure and 24\% smoked, Over 30-40 lakh deaths per year is due to cardiovascular disease. India is now number one in the world in this aspect. The modern medical science has no describing lifelong medications-which too keep on increasing with the passage of time. They are not only expensive but also are having numerous side effects. Surgical option is option in case of heart disease but the cost is prohibitive and the treatment is temporary. Health status of Indian women has to be viewed seriously. Nearly 60,000 women die every year in Pregnancy ; 90\% of working women have irregular periods; junk food causes girls to hit puberty at 7 years; menopause is starting to hit women at 20 's ; $40 \%$ of women are exposed to second hand smoking ; $35 \%$ of women in every 30 s are affected by thyroid problems; 1.21 crore Indian women are 
smokers ; $28 \%$ have the chances to get breast cancer ; $75 \%$ of working women have health problem; More than 90 crore people of India are having either this disease or that disease ; $50 \%$ of the disease can be self controlled ; $83 \%$ of all deaths before 65 years can be preventable; fitness status of Indians is also not appreciable. 85\% of the people lead sedentary life ; $43 \%$ of the children have no fitness ; 35\% of children have less lung efficiency ; $60 \%$ of the children don't have basic movement skills ; 84\% of the adolescent are not doing any physical activity ; only $19 \%$ of the Indians are doing physical exercises that too occasionally; our lung efficiency is $30 \%$ weaker than the Europeans ; children's fitness is very low than their parents when they were in childhood; if a person walks for six minutes or more in $400 \mathrm{~m}$ track. If a person's pace is 24 minutes per miles or more, he or she has to improve his or her health, fitness \& wellness (Chhajer, 2014).

The human body is designed to work best when it is active. It readily adapts to nearly any level of activity and exertion; in fact, physical fitness is defined as a set of physical attributes that allow the body to respond or adapt to the demands and stress of physical effort. The more we ask of our bodies-our muscles, bones, heart, lungs- the stronger and more fit they become. However, the reverse is also true: The less we ask of them, the less they can do. When our bodies are not kept active, they begin to deteriorate. Bones lose their density, joints stiffen, muscles become weak, and cellular energy systems begin to degenerate. To be truly well, human beings must be active.

Unfortunately, a sedentary lifestyle is common worldwide today, More than $60 \%$ of Americans are not regularly physically active, and more than $25 \%$ are not active at all. In India also, a study of the 14227 individuals studied, 54.4\% $(\mathrm{n}=7737)$ were inactive (males: 41.7\%), while 31.9\% $(\mathrm{n}=4537)($ males: $58.3 \%)$ were active and $13.7 \%$ $(\mathrm{n}=1953)$ (males: 61.3\%) were highly active. Subjects were more inactive in urban, compared to rural, areas $(65.0 \%$ vs. $50.0 \%$; $<<0.001)$. Males were significantly more active than females $(\mathrm{p}<0.001)$. Subjects spent more active minutes at work than in the commuting and recreation domains. Absence of recreational activity was reported by $88.4 \%, 94.8 \%, 91.3 \%$ and $93.1 \%$ of the subjects in Chandigarh, Jharkhand, Maharashtra and Tamilnadu respectively. The percentage of individuals with no recreational activity increased with age (Anjana et al., 2014).

\section{Materials and Methods:-}

To achieve the objective of the study, two hundred $(\mathrm{N}=200)$ Indian female students and two hundred $(\mathrm{N}=200$ Foreign male students were selected conveniently and purposely from the regular students of different Universities and Colleges of Delhi State as subjects. The age of the subjects ranged between 17 to 25 years. Physical activity index Questionnaire (B. Mayfield, personal nutrition department USA, 2006) was used to measure physical activity index of students. In order to examine the hypothesis of the present study Mean, SD and Independent sample ' $t$ ' test was applied to compare the mean scores of Indian and Foreign female students on physical activity index. The level of significance was set at 0.05 .

\section{Results and Discussion:-}

The comparison between Indian and Foreign female students on physical activity index was statistically analyzed using ' $t$ ' test. The data pertaining to the same are presented in table- 1 .

Table 1:- Comparison of Scores on physical activity index between Indian female and Foreign female students of Delhi State

\begin{tabular}{|l|l|l|l|l|c|c|c|c|}
\hline Variable & Group & N & Mean & SD & SEM & MD & SED & t-value \\
\hline Physical Activity Index & Indian Female & 200 & 11.10 & 10.82 & .76 & 2.59 & 1.35 & 1.91 \\
\cline { 2 - 9 } & Foreign Female & 200 & 13.69 & 15.78 & 1.11 & & & \\
\hline
\end{tabular}

*Significant at .05 level

' $t$ '.05 $(398)=1.96$

From the result projected in table-1 Indian female students had mean score of 11.10 with S.D=10.82 and S.E.M=.76. Foreign female students had mean 13.69 with S.D=15.78 and S.EM 1.11.Mean difference and S.E.D were 2.59 and 1.35 respectively. $\mathrm{t}$-value was not found to be statistically significant as the value obtained was 1.91 whereas the tabulated value was 1.96 with 398 degree of freedom at .05 level of significance. Mean scores of Indian and Foreign female students of Delhi State on Physical Activity Index is depicted graphically in fig. 1. 


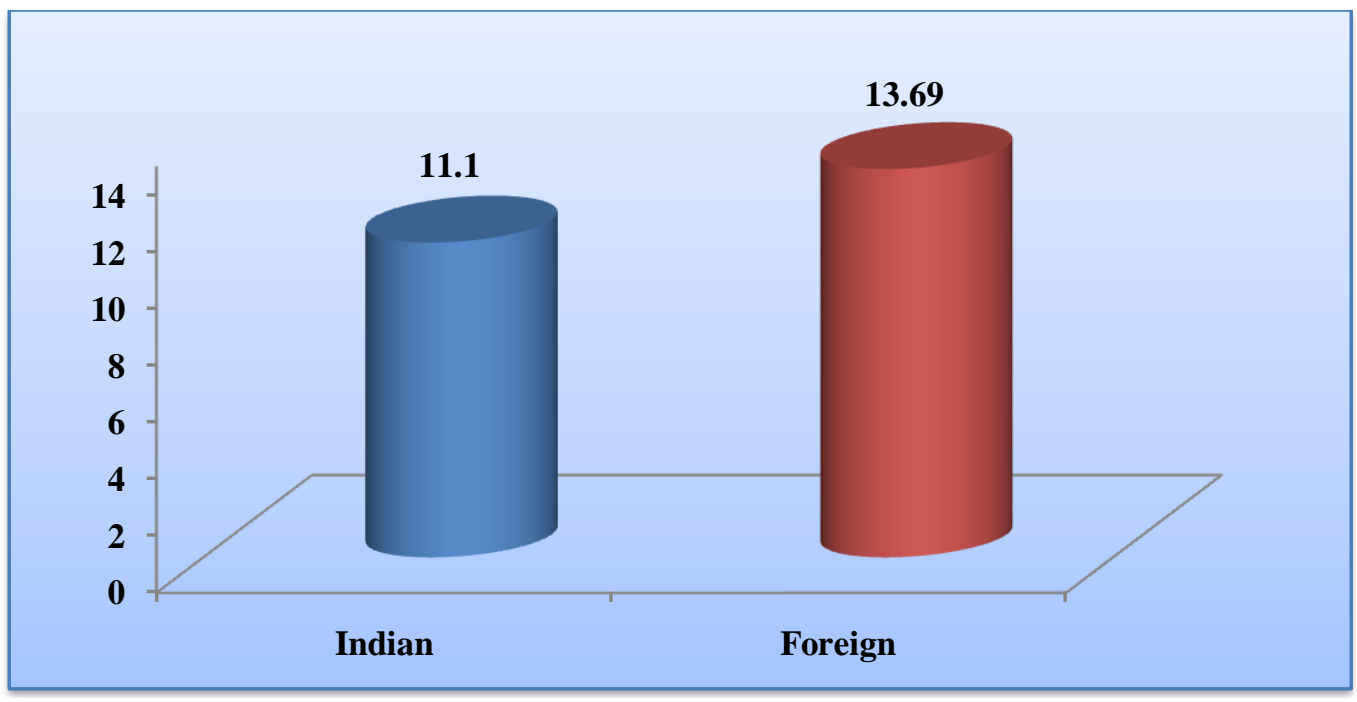

Figure 1:- Mean scores of Indian and Foreign female students of Delhi State on physical activity index

The finding of the study showed that there was no significant difference between Indian female students and foreign female students of different Universities and colleges of Delhi State on physical activity index. Foreign female students have shown higher mean value than Indian female students. The research findings of Anjana et al. (2004), supports the findings of the present study. She concluded that large populations of people in India are inactive with fewer 10\% engaging in recreational physical activity. Singh and Purohit (2012) concluded in their study, those mostly health care professionals were having sedentary lifestyle.

\section{Conclusions:-}

In the light of findings and limitations of present study the following conclusions were drawn.

There was no significant difference between Indian female students and foreign female students of different Universities and Colleges of Delhi State on physical activity index.

Foreign female students were found more active and higher mean value as compare to Indian female students, but both categories found in sedentary lifestyle.

\section{References:-}

1. Anjana, R.M., Pradeepa, R., Das, A.K., Deepa, M., Bhansali, A., Joshi, S.R., Subashini, R. (2014). Physical activity and inactivity pattern in India. International Journal Behavioral Nutrition and Physical activity, 11, 2637.

2. Chhajer, B. (2015, 20-26 June). Yoga for Youth. The way to prevent lifestyle disease. Employment News, vol. xi, pp. 1, 54.

3. Gupta, R., Sharma, K.K., Gupta, A., Aggarwal, A., Mohan, T., Gupta, S. (2012). Persistence high prevalence of cardio vascular risk factors in the urban middle class in India. J Assoc Physician India. 2012,11-26

4. Mayfield, B. (2006). Personal nutrition profile: A diet and activity analysis. Sudbury, MA: Jones and Bartlett Publishers.

5. National health Committee (1998). Active for life: A call for action. National Health Committee, Wellington.

6. Singh, A. \& Purohit, B. (2012). Physical activity, sedentary lifestyle, and obesity among Indian Dental Professional. Journal of Physical Activity and Health 2012, 563-570. 